\title{
Current and future effects of global change on a hotspot's freshwater diversity
}

\author{
Belinda Gallardo a,*, Arthur E. Bogan b , Sahana Harun ' , Leonardo Jainih c, Manuel Lopes-Lima ${ }^{\text {d }}$, \\ Manuel Pizarro ${ }^{a}$, Khairul Adha Rahim ${ }^{\mathrm{e}}$, Ronaldo Sousa ${ }^{\mathrm{f}}$, Salvatore G.P. Virdis ${ }^{\mathrm{g}}$, Alexandra Zieritz ${ }^{\mathrm{h}}$ \\ a Applied and Restoration Ecology Group, Pyrenean Institute of Ecology (IPE-CSIC), 50092 Zaragoza, Spain \\ ${ }^{b}$ Research Laboratory, North Carolina State Museum of Natural Sciences, 11 West Jones Street, Raleigh, NC 27601, USA \\ c Institute for Tropical Biology and Conservation, University Malaysia Sabah (UMS), 88400, Jalan Maktab Sabah, 88100 Kota Kinabalu, Sabah, Malaysia \\ d CIBIO/InBIO - Research Center in Biodiversity and Genetic Resources, University of Porto, Campus Agrário de Vairão, Rua Padre Armando Quintas, $4485-661$ Vairão, Portugal \\ e Department of Aquatic Sciences, Faculty of Resource Science E Technology, University Malaysia Sarawak, 94300 Kota Samarahan, Sarawak, Malaysia \\ f CBMA - Centre of Molecular and Environmental Biology, Department of Biology, University of Minho, Campus Gualtar, 4710-057 Braga, Portugal

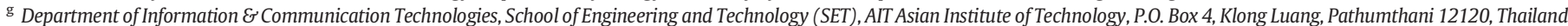 \\ h School of Environmental and Geographical Sciences, University of Nottingham Malaysia Campus, Jalan Broga, 43500 Semenyih, Malaysia
}

\section{H I G H L I G H T S}

- Drivers of freshwater biodiversity loss in the tropics are poorly understood.

- We investigated the effects of deforestation, climate change and invasive species.

- We evaluated multiple future scenarios using ensemble distribution models.

- By 2050, freshwater mussels may lose 20-30\% of their current suitable habitat.

- Native mussels may compete with invasive mussels across $60 \%$ of their range.

- Our projections can guide future expeditions and measures to preserve biodiversity.

\section{G R A P H I C A L A B S T R A C T}

During the past decades, global deforestation for palm oil production has increased dramatically fuelled by growing demands, which, together with on-going climate changes and the unprecedented expansion of invasive species is expected to have catastrophic consequences for biodiversity conservation. Here we focus our attention on freshwater mussels, a vulnerable group facing global declines that provides compelling indications of overall freshwater biodiversity. Using Species Distribution Models based on field data from a recent expedition in the biodiversity hotspot Sundaland, we anticipate major range contractions of native freshwater fauna, and fragmentation of the remaining suitable habitat. Our projections can be used to guide future expeditions to monitor the conservation status of freshwater biodiversity, and potentially reveal populations of potentially extirpated endemic species.

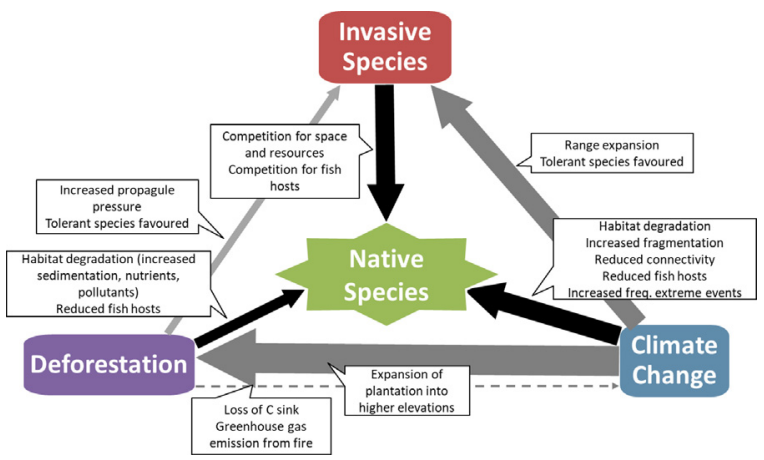

A B S T R A C T

Deforestation, climate change and invasive species constitute three global threats to biodiversity that act synergistically. However, drivers and rates of loss of freshwater biodiversity now and in the future are poorly understood. Here we focus on the potential impacts of global change on freshwater mussels (Order Unionida) in Sundaland (SE Asia), a vulnerable group facing global declines and recognized indicators of overall freshwater biodiversity. We used an ensemble of distribution models to identify habitats potentially suitable for freshwater mussels and their change under a range of climate, deforestation and invasion scenarios. Our data and models revealed that, at present, Sundaland features 47 and 32 Mha of habitat that can be considered environmentally

\section{Article history:}

Received 5 January 2018

Received in revised form 15 March 2018

Accepted 5 April 2018

Available online $\mathrm{xxxx}$

Editor: R Ludwig

\footnotetext{
* Corresponding author at: Pyrenean Institute of Ecology (IPE-CSIC), Avda. Montañana 1005, 50059 Zaragoza, Spain.

E-mail addresses: belinda@ipe.csic.es (B. Gallardo), arthur.bogan@naturalsciences.org (A.E. Bogan), m.pizarro@csic.es (M. Pizarro), akhairul@frst.unimas.my (K.A. Rahim), virdis@ait.asia (S.G.P. Virdis), Alexandra.zieritz@nottingham.edu.my (A. Zieritz).
} 
Keywords:

Climate change

Oil-palm

Sinanodonta woodiana

Species Distribution Models

Habitat fragmentation

Freshwater mussels suitable for native and invasive freshwater mussels, respectively. We anticipate that by 2050, the area suitable for palm oil cultivation may expand between 8 and 44 Mha, representing an annual increase of $2-11 \%$. This is expected to result in a $20 \%$ decrease in suitable habitat for native mussels, a drop that reaches $30 \%$ by 2050 when considering concomitant climate change. In contrast, the habitat potentially suitable for invasive mussels may increase by 44-56\% under 2050 future scenarios. Consequently, native mussels may compete for habitat, food resources and fish hosts with invasive mussels across approximately $60 \%$ of their suitable range. Our projections can be used to guide future expeditions to monitor the conservation status of freshwater biodiversity, and potentially reveal populations of endemic species on the brink of extinction. Future conservation measures-most importantly the designation of nature reserves-should take into account trends in freshwater biodiversity generally, and particularly species such as freshwater mussels, vital to safeguard fundamental ecosystem services.

(c) 2018 Elsevier B.V. All rights reserved.

\section{Introduction}

Deforestation, climate change and invasive species constitute three major threats to biodiversity that are exacerbated by synergistic effects (Brook et al., 2008). Sundaland (encompassing Peninsular Malaysia, Borneo, Sumatra and Java) is a global biodiversity hotspot holding $>80 \%$ of South-East Asia's remaining primary forest (Myers et al., 2000 ). At the same time, Sundaland produces $>80 \%$ of all palm oil consumed globally (Fitzherbert et al., 2008). The consequence is one of the highest rates of deforestation in the world, with oil-palm expansion being the main driver of habitat degradation and biodiversity loss (Sodhi et al., 2004). Beyond terrestrial ecosystems, the expansion of palm plantations degrades freshwater habitats by severely increasing bank erosion and sediment yield, decreasing forest shading and forest litter, and altering water quality (Chellaiah and Yule, 2017; Douglas et al., 1992; Zieritz et al., 2016). Yet, the extraordinary freshwater biodiversity of Sundaland has received little attention. This is alarming, since the richness of endemic and threatened freshwater species is the highest in South-East Asia (Collen et al., 2014), where habitat loss will therefore affect a very significant part of the world's biodiversity (Dudgeon, 2003).

The effects of deforestation are reinforced by on-going climate changes that will further affect freshwater habitat availability and quality over large scales (Meyer et al., 1999). Climate change projections anticipate the warming of Sundaland, showing an increase in annual precipitation with large seasonal and spatial variability, and higher frequency of disturbance events (e.g. storms, floods, droughts) related to El Niño/La Niña cycles (IPCC, 2014). These changes are likely to affect the survival of native freshwater species (Hastie et al., 2003; Poff et al., 2012). Together, deforestation and climate change may also favour the expansion of aquatic invasive species that competitively may displace native populations (Didham et al., 2007). One example is the Chinese pond mussel (Sinanodonta woodiana Lea 1834) that is native to temperate and tropical eastern Asia, primarily the Amur and Yangtze river basins (Kraszewski and Zdanowski, 2007; Soroka, 2005). The species has spread considerably over the last decades in Asia, Europe and the Americas driven by intentional and unintentional introductions as a food source, for ornamental purposes and attached to their fish hosts, so that in Malaysia it is now considered the most widespread freshwater mussel species (Zieritz et al., 2018).

As a consequence of these interacting threats, the distribution of native freshwater mussels (Bivalvia: Unionida) has contracted considerably over recent decades in Sundaland, and will likely continue to do so in the future (Zieritz et al., 2016). Recent expeditions to Malaysian Borneo failed to confirm the presence of four of its five endemic species, which are possibly extinct (Zieritz et al., 2018). Since freshwater mussels are indicators of habitat quality and overall freshwater biodiversity (Aldridge et al., 2007), we may expect similar decreasing patterns for other freshwater taxa. Indeed, two whole orders of insects (Coleoptera and Hemiptera) were reported to be absent from streams flowing through oil palm plantations in Malaysia, in comparison to rainforest streams (Mercer et al., 2014). Likewise, fish biomass, richness and functional diversity declined markedly in streams that lost their riparian buffer due to deforestation (Giam et al., 2015), with 77\% estimated loss of species in the future if current rates of deforestation are maintained (Giam et al., 2012). In spite of these figures, the effects of deforestation on freshwater biodiversity in Sundaland, and more generally tropical Asia, have received little attention (Dudgeon, 2003), let alone their synergistic interaction with other drivers of change.

For the first time, here we anticipate the collective consequences of oil-palm plantation expansion, climate change and invasive species on the distribution of native freshwater mussels and, by extension, freshwater biodiversity in Sundaland. In particular, this study aims to quantify the relative importance of major drivers of freshwater biodiversity loss in Sundaland, and to spatially identify regions of particular concern for freshwater mussel conservation under global change. Maps can be further used to direct future expeditions to monitor the conservation status of freshwater biodiversity, and potentially discover relict populations of endemic species. In the light of our results, we finally discuss the synergistic consequences of global change upon the conservation of freshwater biodiversity in a global hotspot where many species have recently become extremely rare, possibly extinct.

\section{Material and methods}

This study focuses on Sundaland, including Peninsular Malaysia, Borneo, Java and Sumatra. Sundaland is recognized as one of the most important global biodiversity hotspots (Myers et al., 2000). The region is also undergoing exceptional loss of habitat due to human activities (logging, slash-and-burn agriculture, oil-palm plantations), and retains only $8 \%$ of its primary forests (Myers et al., 2000). To investigate the potential consequences of oil-palm expansion, climate change and invasive species on the distribution of native freshwater mussels, we used Species Distribution Models (SDM). This technique uses as input the occurrence of species and the set of factors that might affect the likelihood of species establishment. Once calibrated, the model extrapolates the environmental preferences of the species onto the region of interest, identifying areas at continental or regional scale that are environmentally most similar to the current range of the species (Guisan and Thuiller, 2005).

\subsection{Mussel occurrence}

Data on the presence/absence of freshwater mussels in Malaysia (i.e. Peninsular Malaysia, and Sarawak and Sabah in northern Borneo) were collected in surveys conducted between 2014 and 2016 (Zieritz et al., 2016, 2018). A total of 227 sites were surveyed (155 in Peninsular Malaysia and 72 in Borneo), covering 35 river basins and a wide diversity of freshwater habitats: rivers, creeks, canals, rice-paddy run-offs, lakes, reservoirs and ponds (Fig. 1). After intensive sampling effort, nine native freshwater mussels were identified: Contradens contradens (Lea, 1838), Hyriopsis bialata (Simpson, 1900), Physunio superbus (Lea, 
1843), Pilsbryoconcha compressa (Martens, 1860), Pilsbryoconcha exilis (Lea, 1838), Pseudodon cambodjensis (Petit, 1865), Pseudodon cumingii (Lea, 1850), Pseudodon vondembuschianus (Lea, 1840), and Rectidens sumatrensis (Dunker, 1852). At the local scale, native mussels in Malaysia showed preference for relatively low $\mathrm{pH}$, phosphate and ammoniacal nitrogen, which are often associated with pristine aquatic environments (Zieritz et al., 2016, 2018). Considering the similar environmental preferences displayed by the nine native mussels and low occurrence frequency of individual species (between 2 and 22 sites), we decided to group all nine native species for modelling. Limitations associated with this decision are acknowledged in the Discussion section. The invasive Chinese pond mussel was found in 33 sites in an extremely wide variety of habitats, ranging from concrete eutrophic ponds to fishing ponds, small streams and medium-sized rivers (Zieritz et al., 2018).

In the lack of published studies about the direct and indirect interaction between native and invasive mussels, and following a precautionary approach, here we assume that the effects of $S$. woodiana on native freshwater biodiversity are negative, particularly in heavily modified and artificial habitats (Paunovic et al., 2006; Sousa et al., 2014; Zieritz et al., 2016). First, invasive mussels are more tolerant than natives to the disturbed environmental conditions of waterbodies affected by
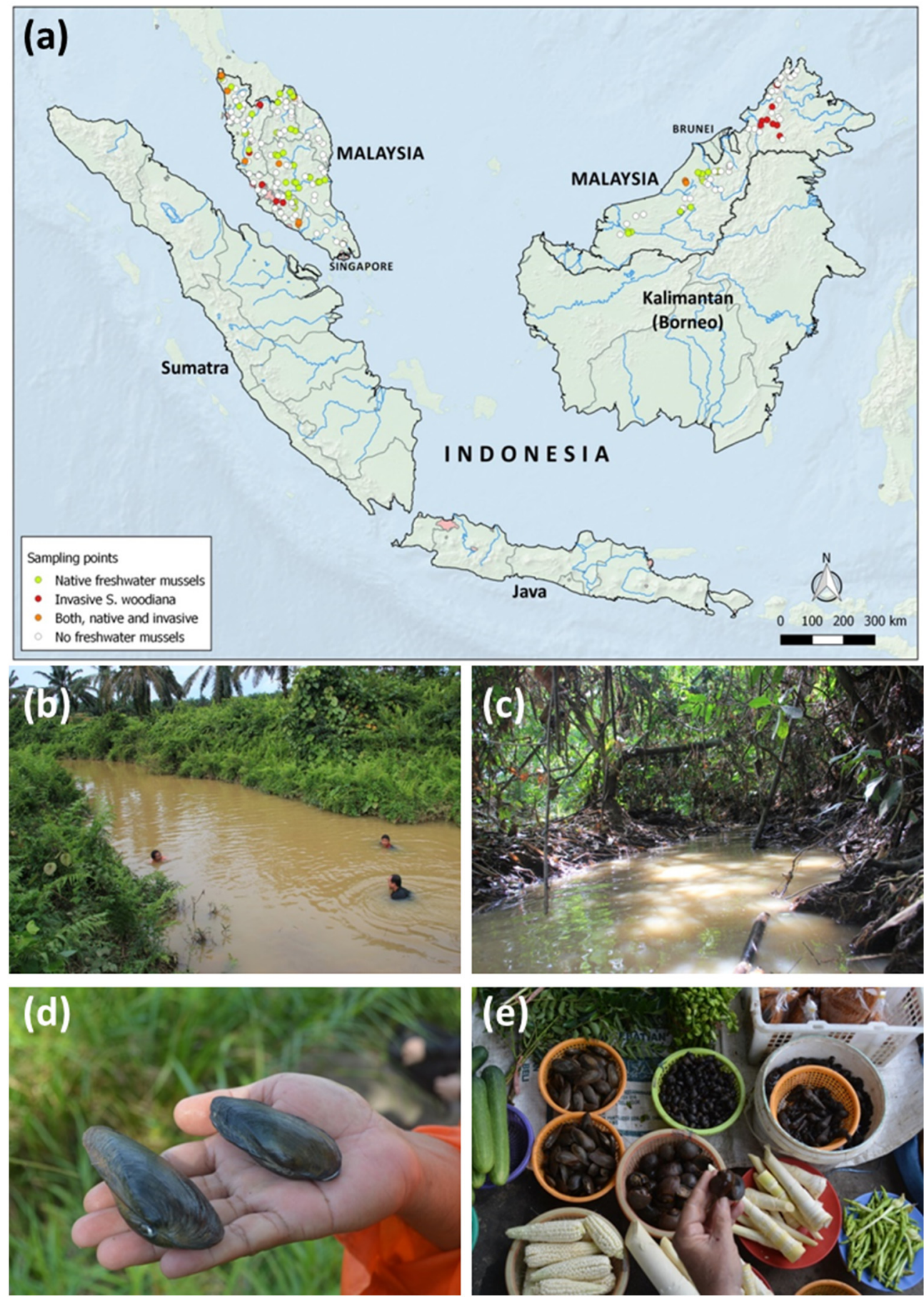

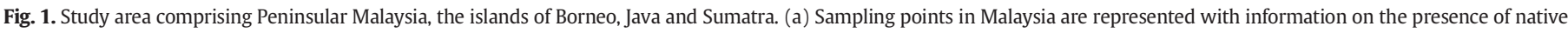

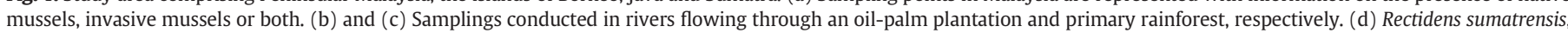
one of the native freshwater mussels collected during the campaign. (e) Freshwater mussels and snails being sold in a market at Kanowit, Sarawak, Malaysia. 
deforestation, and will compete for habitat and resources with native mussels (Paunovic et al., 2006; Sousa et al., 2014). Second, invasive mussels seem to use a wide diversity of hosts, which constitutes an additional and fundamental competitive advantage over native mussels for reproduction and spread (Donrovich et al., 2017). Third, the expansion of invasive species, tightly linked to human activities, usually overcomes traditional dispersal barriers, being able to occupy all of their climatic niche in the long term (Capinha et al., 2015), whereas native mussels are strongly dispersal-limited (Lopes-Lima et al., 2017).

\subsection{Predictors of mussel distribution}

As potential predictors of the spatial distribution of freshwater mussels we explored a total of 35 climatic, environmental and human variables (sources of information and other details in Tables 1 and S1, Supplementary material). We extracted the corresponding value of each potential predictor from each of the 227 sampling sites in Malaysia using Geographic Information Systems (Q-GIS v 10.2). Zieritz et al. (2018) showed the relative contribution of water quality and landscape characteristics to the probability of presence of native vs. invasive mussels in northern Borneo. In particular, high precipitation and organic content of soils favoured the presence of native mussels; whereas human activities (proximity to roads, human population, \% anthropogenic land cover) increased the probability of presence of $S$. woodiana at the local scale (Zieritz et al., 2018). Despite water quality and hydrological characteristics are not available at the large-scale used here, recent investigations have demonstrated that predictions based on climate are not fundamentally different from predictions based on instream water temperature and discharge (McGarvey et al., 2017).

Identifying the most appropriate variables for modelling is crucial to maximize the accuracy of distribution models and their projection in space and time. In this study, predictors were selected based on a combination of statistical performance and ecological relevance, as suggested by Dormann et al. (2013) (see Tables S2-S3 and Fig. S1). Final variables considered for modelling included: temperature seasonality, maximum temperature of the warmest month (i.e. maximum temperature), minimum temperature of the coldest month (i.e. minimum temperature), precipitation of the wettest month (i.e. maximum precipitation), aridity, altitude, soil $\mathrm{pH}$, soil fraction of organic material and sand, the Human Influence Index, distance to transportation networks and distance to oil-palm plantations (see a brief description of variables in Table 1). We decided to include altitude that is often excluded from climate change models because freshwater mussels mostly inhabit lowlands. Altitude showed a correlation of $r \leq 0.62$ with other climate predictors used in the models, and several authors have found altitude to be relevant to explain the distribution of freshwater taxa (e.g. Gallardo and Aldridge, 2013b; Gallardo et al., 2012). Despite the inclusion of the Human Influence Index, which may partially account for the effects of roads $(r$ $=-0.61$ ), we included distance to transportation networks separately because of its importance to explain the expansion of S. woodiana (Zieritz et al., 2018).

We used the non-parametric Kruskal-Wallis test with R-CRAN 3.1.3 ( $\mathrm{R}$ Core Team, 2017) to explore differences in key predictors among

Table 1

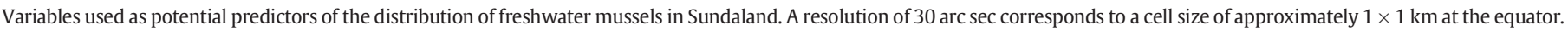
See the complete list of variables and range of values in the study area in Table S1.

\begin{tabular}{|c|c|c|c|c|c|}
\hline Variable & Details & Relevance & $\begin{array}{l}\text { Resolution } \\
\text { and extent }\end{array}$ & Scenario & Source \\
\hline Climate & $\begin{array}{l}19 \text { bioclimatic variables combining monthly } \\
\text { temperature and precipitation. } \\
\text { Additionally, aridity }{ }^{\mathrm{a}} \text { was calculated as the } \\
\text { ratio between mean annual temperature and } \\
\text { precipitation. }\end{array}$ & $\begin{array}{l}\text { Temperature affects the reproduction, } \\
\text { survival, growth and dispersal of aquatic } \\
\text { organisms. Precipitation affects the } \\
\text { availability of water and the occurrence of } \\
\text { floods and droughts. }\end{array}$ & $\begin{array}{l}30 \text { arc sec } \\
\text { Global }\end{array}$ & $\begin{array}{l}\text { Present } \\
2050 \text { opt } \\
2050 \text { pes } \\
\text { (see text for } \\
\text { details) }\end{array}$ & $\begin{array}{l}\text { WorldClim-Global Climate } \\
\text { Data http://www. } \\
\text { worldclim.org/bioclim }\end{array}$ \\
\hline Topographic & $\begin{array}{l}\text { Five variables: altitude, slope }{ }^{\mathrm{a}} \text {, terrain } \\
\text { ruggedness index }\left(\mathrm{TRI}^{\mathrm{a}}\right) \text {, and flow } \\
\text { accumulation }^{\mathrm{a}} \text {. }\end{array}$ & $\begin{array}{l}\text { Freshwater mussels usually inhabit lowland } \\
\text { areas. Slope can affect water velocity. TRI and } \\
\text { flow accumulation can affect habitat } \\
\text { heterogeneity and availability. }\end{array}$ & $\begin{array}{l}30 \text { arc sec } \\
\text { Global }\end{array}$ & $\begin{array}{l}\text { Present } \\
\text { Assumed constant } \\
\text { under future } \\
\text { conditions }\end{array}$ & $\begin{array}{l}\text { US Geological Survey } \\
\text { https://lta.cr.usgs. } \\
\text { gov/GMTED2010 }\end{array}$ \\
\hline Geology & $\begin{array}{l}\text { One variable with seven bedrock geologies: } \\
\text { endogenous plutonic or metamorphic rocks, } \\
\text { extrusive volcanic rocks, ophiolitic complex, } \\
\text { sedimentary rocks and undifferentiated facies. }\end{array}$ & $\begin{array}{l}\text { Bedrock geology can affect water } \\
\text { characteristics ( } \mathrm{pH} \text {, salinity) that are key for } \\
\text { freshwater mussels. }\end{array}$ & $\begin{array}{l}30 \text { arc sec } \\
\text { Global }\end{array}$ & $\begin{array}{l}\text { Present } \\
\text { Assumed constant } \\
\text { under future } \\
\text { conditions }\end{array}$ & $\begin{array}{l}\text { Geological Map of the } \\
\text { World http://ccgm.free.fr/ }\end{array}$ \\
\hline Soil & $\begin{array}{l}\text { Five variables: pH, \% organic carbon, \% sand, \% } \\
\text { silt and \% clay. }\end{array}$ & $\begin{array}{l}\text { Soil characteristics affect habitat availability } \\
\text { and water chemistry. }\end{array}$ & $\begin{array}{l}30 \text { arc sec } \\
\text { Global }\end{array}$ & $\begin{array}{l}\text { Present } \\
\text { Assumed constant } \\
\text { under future } \\
\text { conditions }\end{array}$ & $\begin{array}{l}\text { ISRIC-World Soil } \\
\text { Information } \\
\text { https://soilgrids.org }\end{array}$ \\
\hline $\begin{array}{l}\text { Human } \\
\text { Influence } \\
\text { Index (HII) }\end{array}$ & $\begin{array}{l}\text { A combination of human population } \\
\text { distribution, urban areas, roads, navigable } \\
\text { rivers, and various agricultural land uses } \\
\text { presumed to exert an influence on } \\
\text { ecosystems. }\end{array}$ & $\begin{array}{l}\text { HII may negatively affect native species while } \\
\text { at the same time promoting the spread of } \\
\text { invasive species. }\end{array}$ & $\begin{array}{l}30 \text { arc sec } \\
\text { Global }\end{array}$ & $\begin{array}{l}\text { Present } \\
\text { Assumed constant } \\
\text { under future } \\
\text { conditions }\end{array}$ & $\begin{array}{l}\text { Socio-Economic Data and } \\
\text { Applications Centre, } \\
\text { http://sedac.ciesin. } \\
\text { columbia.edu (Sanderson } \\
\text { et al., 2002) }\end{array}$ \\
\hline Urban areas & Distance (in $\mathrm{km}$ ) to closest village ${ }^{\mathrm{a}}$ & $\begin{array}{l}\text { Closeness to cities increases the probability of } \\
\text { intentional introduction (e.g. as food source) } \\
\text { of the invasive mussel. }\end{array}$ & $\begin{array}{l}30 \text { arc sec } \\
\text { Global }\end{array}$ & $\begin{array}{l}\text { Present } \\
\text { Assumed constant } \\
\text { under future } \\
\text { conditions }\end{array}$ & $\begin{array}{l}\text { Global Maps } \\
\text { https://globalmaps.github. } \\
\text { io/datasets.html }\end{array}$ \\
\hline Transportation & $\begin{array}{l}\text { Distance (in } \mathrm{km} \text { ) to closest transportation } \\
\text { network (roads, railways) }\end{array}$ & $\begin{array}{l}\text { Roads can facilitate access to water-bodies, } \\
\text { increasing the risk of intentional or accidental } \\
\text { introduction of the invasive mussel. }\end{array}$ & $\begin{array}{l}30 \text { arc sec } \\
\text { Global }\end{array}$ & $\begin{array}{l}\text { Present } \\
\text { Assumed constant } \\
\text { under future } \\
\text { conditions }\end{array}$ & $\begin{array}{l}\text { Global Maps } \\
\text { https://globalmaps.github. } \\
\text { io/datasets.html }\end{array}$ \\
\hline Land-use & $\begin{array}{l}\text { Distance (in } \mathrm{km} \text { ) to current plantations of oil } \\
\text { palm }^{\mathrm{a}}\end{array}$ & $\begin{array}{l}\text { Closeness to oil-palm may negatively affect } \\
\text { native mussels (e.g. bank erosion, poor water } \\
\text { quality). The invasive mussel is more tolerant } \\
\text { to such disturbance. }\end{array}$ & $\begin{array}{l}30 \text { arc sec } \\
\text { SE Asia }\end{array}$ & $\begin{array}{l}\text { Present } \\
\text { Optimistic and } \\
\text { pessimistic }^{\mathrm{a}} \text { future } \\
\text { scenarios (see } \\
\text { Material and } \\
\text { methods) }\end{array}$ & Miettinen et al. (2016) \\
\hline
\end{tabular}

a Variables calculated using Geographic Information Systems (Q-GIS v 10.2). 
sites occupied by: native mussels, invasive mussels, both native and invasive, and without presence of any mussel.

\subsection{Species Distribution Models}

Ensemble Species Distribution Models were performed using package BIOMOD2 version 3.1-64 (BIOdiversity MODelling) (Thuiller et al., 2014) in R-CRAN 3.1.3 (R Core Team, 2017). A graphic summary of the workflow and description of model settings can be consulted in Suppl. material (Fig. S2). SDMs were calibrated with data on the occurrence of the species, which in this case corresponds to sampling sites inhabited by native or invasive mussels, respectively. We used real absence information obtained systematically during field sampling to discern the environmental preferences of the species. Using real absence information (as opposed to the common selection of "pseudo-absences") ensures that any sampling bias affecting presences (e.g. sampling conducted in Malaysia but not the rest of Sundaland, sampling biased towards accessible areas) is compensated by a similar bias in absence information (Phillips et al., 2009), and may partially compensate for overfitting due to the large number of predictors used. The prevalence of ensemble models is set to 0.5 so that presences and absences have equal weight in the model (Barbet-Massin et al., 2012).

To evaluate the effect of oil-palm plantations on freshwater mussel distribution, we calibrated two sets of ensemble models: with and without including distance to current oil-palm plantations as a factor. This is based on the basic assumption that closeness to oil-palm plantations negatively affects native mussels (e.g. higher probability of bank erosion and water pollution), but may favour the introduction of invasive mussels (e.g. higher propagule pressure and higher disturbance). This makes a total of 4 ensemble models combining native and invasive species, with and without oil-palm as a predictor.

After calibration, the four ensemble models were projected onto Sundaland to obtain suitability maps that range from 0 (unsuitable) to 1000 (very suitable). Continuous maps were transformed into binary suitable/unsuitable maps using a threshold, as described in Suppl. mat.

Following the methodology proposed by Gallardo and Aldridge (2013a), we overlapped native and invasive binary maps and calculated the area occupied by: 1 ) "Refugia", defined as areas suitable for native freshwater mussels but unsuitable for colonization by their invasive counterparts. 2) "Under risk of invasion", areas suitable for invasion but (apparently) unsuitable for the native species investigated in this study. 3) "Conflict", delineated as areas considered suitable for both native and invasive species.

\subsection{Future scenarios of climate and land-use change}

SDMs were projected onto future scenarios to evaluate potential changes in habitat suitability for native and invasive mussels due to changes in climate and oil-palm expansion. Two 2050 climate change scenarios were considered: one "optimistic" and one "pessimistic", considering a future world with very low or very high greenhouse gas concentration levels, respectively (IPCC, 2014). Likewise, two 2050 oil-palm expansion scenarios were constructed (see suppl. Material for more information): one "optimistic" scenario considering limited expansion of palm plantations into the most suitable -and therefore productiveareas of Sundaland (Fig. 2b); and another "pessimistic" scenario assuming large expansion of oil-palm plantations into areas showing the minimum climatic and environmental (administrative, topographic, soil $\mathrm{pH}$ ) conditions for plantation (Fig. 2c). Large areas predicted by our models as suitable for palm-expansion in Sundaland (Fig. 2) largely coincide with previous attempts to project future land-use scenarios in the region (Brodie, 2016; Struebig et al., 2015).

A full description of climate change and oil-palm scenarios used in this study can be found in Suppl. material.

\subsection{A global model for S. woodiana}

Regional models allow using variables known to affect the largescale distribution of species that are often not available at larger scales, such as distance to oil-palm in our specific case. However, regional models can seriously underestimate the full potential for invasion, particularly for species with broad tolerance, such as S. woodiana. For this reason, experts recommend calibrating models using the complete global known distribution of the species (Broennimann and Guisan, 2008 among others; Gallardo et al., 2013). According to Gallien et al. (2012), the comparison of results obtained in regional and global models can provide important insights into the current stage of the invasion (i.e. quasi-equilibrium, stable, disequilibrium), future dynamics (filling or unfilling potential niches) and potential for future colonization.

To calibrate a global model for S. woodiana, we complemented our regional data on the mussel's presence in Malaysia with data from museum collections, the Global Biodiversity Information Facility (GBIF, http://www.gbif.org/), the Mussel Project Database (http://musselproject.uwsp.edu/, Graf \& Cummings, 2015), and a comprehensive literature review (see Suppl. material). We obtained a total of 667 records from around the world. After removing duplicates (more than one record per spatial unit of 30 arc sec, $1 \times 1 \mathrm{~km}$ approximately) we calibrated the global model with 516 unique data points. We used the same predictors (but at global coverage as opposed to regional scale, see Table 1) and modelling settings as in the regional model, with the only exception of distance to oil-palm that was not available at the global scale.

\section{Results}

Overall, the distribution of native freshwater mussels in our study area was favoured by high temperature and precipitation, low altitude, and soils with more silt and clay than sand in their composition (Table 2). Native freshwater mussels did not show any association with human variables such as the Human Influence Index, proximity to populations and transportation (Table 2).

On the other hand, invasive species showed preference for areas with relatively lower temperature and precipitation, higher altitude and soils with higher sand content than sites colonized by native species (Table 2). Invasive species colonized areas close to transportation networks - an indicator of propagule pressure - but showed no correlation with the Human Influence Index, or with proximity to human populations (Table 2).

The accuracy of SDMs for native and invasive freshwater mussel species was excellent (Table 3). Climate variables were the most important predictors of species distribution in all cases. Beyond climate, environmental variables were particularly relevant for native mussels (overall altitude and precipitation), whereas human-related variables were influential for invasive mussels. In particular, distance to oil-palm plantations was four times more important for invasive than for native mussels (Table 3 ). The response of suitability for native and invasive mussels to the variables used as predictors can be consulted in Figs. S4 and S5, respectively.

The area predicted as suitable for native and invasive mussels under the present reference scenario is 46.6 Mha and 31.7 Mha respectively (Table 3, models 1 and 3), evidently limited to waterbodies within these broad suitable areas. Distribution models indicated that, under current climate conditions, the expansion of oil palm plantations can reduce the area suitable for native mussels by $20 \%$ (Table 3, model 2) (Fig. 3a and b), while expanding the potential distribution of the invasive mussel ( $+19 \%$, Table 3, model 4 ) (Fig. 3c and d). The model based on the species' global distribution indicated an even larger potential spread of the invader (Table 3, model 5).

Focusing on the role of climate change alone, our models anticipate a reduction in the area suitable for native mussels of $23-30 \%$ by 2050 
(a) Current Oil-palm plantations

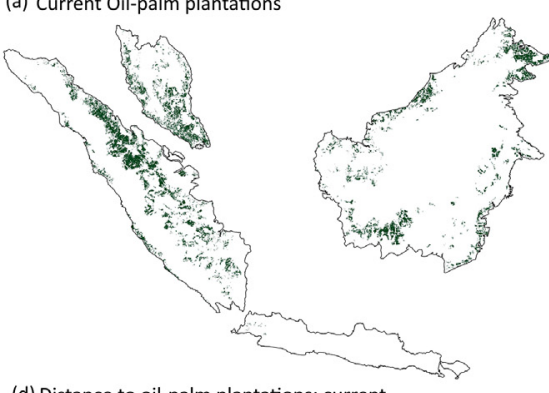

(d) Distance to oil-palm plantations: current

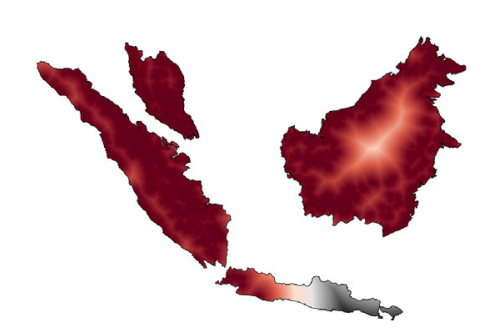

Current and projected palm plantations (b) Optimistic Scenario for oil-palm expansion

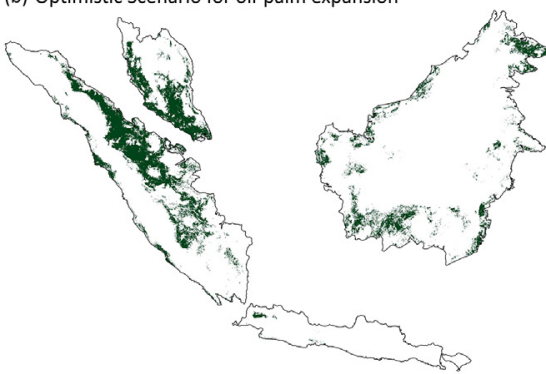

(e) Distance to oil-palm plantation: optimistic scenario

(c) Pessimistic Scenario for oil-palm expansion

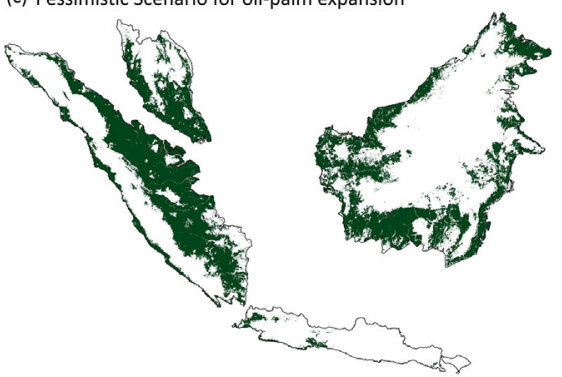

(f) Distance to oil-palm plantation: pessimistic scenario
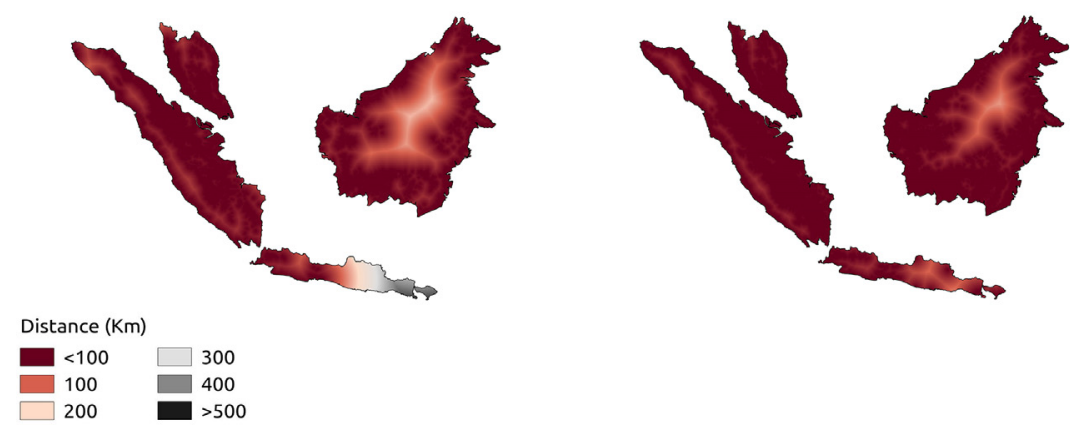

$200>500$

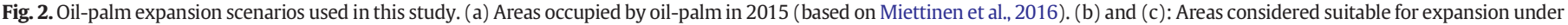
an optimistic and pessimistic scenario (see text for more details). ( $\mathrm{d}$ to f): Distance to current and projected plantations.

depending on an optimistic or pessimistic evolution of greenhouse gas emissions (Table 3, model 1), while at the same time expanding the area suitable for $S$. woodiana by $44-56 \%$ (Table 3, model3).

At present, large areas close to the coast that are deemed suitable for both native and invasive species show a total overlap (i.e. conflict) of $43 \%$ (Fig. 3e). Refugia for native mussels are concentrated towards the east coast of Java and Sumatra and the west coast of Borneo (Fig. 3e). By 2050 , the areas of potential conflict between native and invasive freshwater mussels increase to $58-59 \%$ of the native range, depending on the scenario. Areas under high risk of future invasion are located in the west coast of Java and Sumatra, and East of Borneo (Fig. 3e). Invasive species are able to occupy areas at higher altitudes than natives, and this is reflected in predictions that show large high-altitude areas in Borneo and Java under risk of invasion.

It is interesting to note the substantial uncertainty associated with large inland areas at high altitude and slope, particularly for the native mussels (Fig. S6). Uncertainty is lower in the case of invasive mussels, probably reflecting their broader environmental niche.

\section{Discussion}

\subsection{Effects of deforestation on freshwater diversity in Sundaland}

The destruction, fragmentation or modification of habitat is considered the most important driver behind the decline of freshwater mussels during the last century (Bogan, 2008; Williams et al., 1993). In Sundaland, habitat alteration can be mostly-but not only-attributed to the ongoing conversion of lowland rainforest to cultivate oil palm (Koh and Wilcove, 2008). There are currently 11 Mha of oil palm plantations in Sundaland (Miettinen et al., 2016), and our models anticipate an expansion of 8-44 Mha by 2050 in the area suitable for oil palm cultivation, depending on scenario. This represents an annual increase of

Table 2

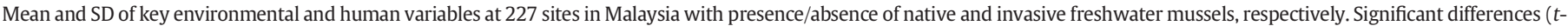
test) between sites colonized by native and invasive freshwater mussel species are indicated in the last column.

\begin{tabular}{|c|c|c|c|c|c|}
\hline & \multicolumn{2}{|c|}{ Native species } & \multicolumn{2}{|l|}{ Invasive species } & \multirow[t]{2}{*}{$t$-Test } \\
\hline & Present & Absent & Present & Absent & \\
\hline Temperature seasonality & $4.89 \pm 1.51$ & $4.43 \pm 1.56$ & $4.21 \pm 1.26$ & $4.62 \pm 1.60$ & $\mathrm{t}=3.20, \mathrm{df}=55.4, \mathrm{p}=0.002$ \\
\hline Maximum $\mathrm{T}\left({ }^{\circ} \mathrm{C}\right)$ & $32.2 \pm 9$ & $31.7 \pm 13.9$ & $31.7 \pm 14.9$ & $31.9 \pm 12.7$ & $\mathrm{t}=3.07, \mathrm{df}=26.3, \mathrm{p}=0.004$ \\
\hline Minimum $\mathrm{T}\left({ }^{\circ} \mathrm{C}\right)$ & $21.5 \pm 8.6$ & $21.5 \pm 10.6$ & $21.6 \pm 8.8$ & $21.5 \pm 10.3$ & n.s. \\
\hline Annual precipitation (mm) & $2708 \pm 694$ & $2661 \pm 636$ & $2352 \pm 518$ & $2729 \pm 656$ & $\mathrm{t}=4.34, \mathrm{df}=65.91, \mathrm{p}<0.001$ \\
\hline Maximum precipitation (mm) & $362 \pm 98$ & $360 \pm 113$ & $298 \pm 86$ & $372 \pm 109$ & $\mathrm{t}=5.02, \mathrm{df}=60.58, \mathrm{p}<0.001$ \\
\hline Aridity & $9.57 \pm 2.50$ & $9.67 \pm 2.59$ & $9.81 \pm 2.55$ & $8.39 \pm 1.97$ & $\mathrm{t}=2.70, \mathrm{df}=36.69, \mathrm{p}=0.01$ \\
\hline Altitude (m) & $49.3 \pm 39.2$ & $127.4 \pm 169.8$ & $141.1 \pm 160.1$ & $100.8 \pm 148.9$ & $\mathrm{t}=-4.06, \mathrm{df}=21.00, \mathrm{p}<0.001$ \\
\hline Soil Silt content (\%) & $26.2 \pm 2.8$ & $25.1 \pm 2.5$ & $26.1 \pm 3.0$ & $25.3 \pm 2.6$ & n.s. \\
\hline Soil pH & $4.9 \pm 2.2$ & $4.9 \pm 2.5$ & $5.0 \pm 2.0$ & $4.9 \pm 2.5$ & n.s. \\
\hline Soil Organic content (\%) & $58.9 \pm 33.2$ & $58.8 \pm 29.6$ & $64.3 \pm 38.9$ & $57.9 \pm 28.9$ & n.s. \\
\hline Sand content $(\%)$ & $40.3 \pm 4.4$ & $41.9 \pm 3.3$ & $41.8 \pm 4.6$ & $41.4 \pm 3.5$ & $\mathrm{t}=-2.29, \mathrm{df}=41.18, \mathrm{p}=0.03$ \\
\hline Clay content (\%) & $33.6 \pm 3.3$ & $33.0 \pm 2.4$ & $32.1 \pm 3.2$ & $33.4 \pm 2.6$ & $\mathrm{t}=2.61, \mathrm{df}=42.78, \mathrm{p}=0.01$ \\
\hline Distance transport (km) & $75 \pm 140$ & $66 \pm 143$ & $13 \pm 28$ & $78 \pm 152$ & $\mathrm{t}=2.81, \mathrm{df}=60.35, \mathrm{p}<0.01$ \\
\hline Distance population (km) & $59 \pm 56$ & $55 \pm 67$ & $72 \pm 97$ & $54 \pm 56$ & n.s. \\
\hline Human Influence Index & $21.7 \pm 12.0$ & $19.4 \pm 9.9$ & $21.9 \pm 10.9$ & $19.6 \pm 10.4$ & n.s. \\
\hline
\end{tabular}




\section{Table 3}

Statistics resulting from Species Distribution Models used to investigate habitat suitability for freshwater mussels in Sundaland. For each group of species (native vs. invasive), two regional models are calibrated: excluding distance to oil-palm as predictor (models 1 and 3), and including it (models 2 and 4). The global model for the invasive species (5) includes records of the species at the global scale. The 2050 opt scenario considers a decrease in greenhouse gas emissions (RCP 2.6), and limited expansion of current oil-palm plantations ( $8.3 \mathrm{Mha}$ ). The 2050 pes scenario assumes increasing greenhouse concentration levels (RCP 8.5) and substantial expansion of oil-palm plantations (44 Mha). $\mathrm{N}=$ number of presences and absences used to calibrate models. TSS = accuracy of the model (range from 0 to 1). Variable importance (range from 0 to 1 ) measures the influence of the variable in the model. The sum of all variable's importance may exceed 1 because of shared variance explained among predictors. Range size: total area (in million hectares) classified as suitable for the species under each scenario. More details about each model in the text.

\begin{tabular}{|c|c|c|c|c|c|c|}
\hline & \multirow{2}{*}{$\begin{array}{l}\text { Model \# } \\
\text { Species }\end{array}$} & 1 & 2 & 3 & 4 & \multirow[t]{2}{*}{5} \\
\hline & & \multicolumn{2}{|c|}{ Native } & \multicolumn{2}{|c|}{ Invasive } & \\
\hline & Scale & \multicolumn{2}{|c|}{ Regional } & \multicolumn{2}{|c|}{ Regional } & Global \\
\hline & $\mathrm{N}$ presences & 59 & 59 & 33 & 33 & 516 \\
\hline & $\mathrm{N}$ absences & 166 & 166 & 192 & 192 & 10,000 \\
\hline & TSS & 0.79 & 0.89 & 0.92 & 0.92 & 0.91 \\
\hline \multirow{12}{*}{$\begin{array}{l}\text { Variable } \\
\text { importance }\end{array}$} & Temp. seasonality & 0.22 & 0.21 & 0.02 & 0.05 & 0.33 \\
\hline & Maximum temp. & 0.004 & 0.01 & 0.06 & 0 & 0.29 \\
\hline & Minimum temp. & 0.17 & 0.13 & 0.22 & 0.01 & 0.32 \\
\hline & Maximum prec. & 0.25 & 0.23 & 0.35 & 0.32 & 0.05 \\
\hline & Aridity & 0.19 & 0.09 & 0.06 & 0.29 & 0.04 \\
\hline & Altitude & 0.47 & 0.47 & 0.03 & 0 & 0.08 \\
\hline & Soil pH & 0.001 & 0 & 0.04 & 0 & 0 \\
\hline & Soil organic carbon & 0.1 & 0.06 & 0.13 & 0.05 & 0.03 \\
\hline & Soil sand & 0.17 & 0.13 & 0.16 & 0 & 0.01 \\
\hline & $\begin{array}{l}\text { Distance to } \\
\text { transportation }\end{array}$ & 0.29 & 0.34 & 0.24 & 0.22 & 0.03 \\
\hline & Human Influence Index & 0.001 & 0 & 0.16 & 0 & 0.21 \\
\hline & Distance to oil-palm & - & 0.04 & - & 0.16 & - \\
\hline \multirow[t]{3}{*}{ Range size (Mha) } & Current scenario & 46.6 & 37.4 & 31.7 & 37.8 & 59.9 \\
\hline & 2050 opt scenario & 35.8 & 29.8 & 45.8 & 46.3 & 55.2 \\
\hline & 2050 pes scenario & 32.5 & 32.3 & 49.3 & 48.9 & 50.3 \\
\hline
\end{tabular}

-: distance to oil-palm not considered in models 1,3 and 5 .

2-11\%, matching the $9 \%$ registered over past years (Wicke et al., 2011). The direct and indirect consequences for biodiversity conservation of such high rates of deforestation are potentially catastrophic (Sodhi et al., 2004). A comprehensive data review by Fitzherbert et al. (2008) found that conversion from primary forest to oil palm leads to a $85 \%$ drop in terrestrial species richness, with greatest changes occurring in mammals (99\%, Yue et al., 2015), ground-dwelling ants (95\%, Brühl and Eltz, 2010), forest birds (90-95\%, Danielsen and Heegaard, 1995) and bats (75-87\%, Danielsen and Heegaard, 1995). In contrast, the large-scale effects of oil palm expansion on freshwater taxa are not known, although some small-scale studies suggest a 65\% decrease in the richness of macroinvertebrates (Mercer et al., 2014), 42\% of fish (Giam et al., 2015), and 83\% of riparian vegetation (Chellaiah and Yule, 2017).

In our study, the total area of Sundaland considered environmentally suitable for the presence of native freshwater mussels decreases noticeably (by 20\%) when considering the effects of oil palm plantations. Native freshwater mussels are particularly sensitive to deforestation because increased turbidity and sedimentation impair their filtration activity, growth and reproduction (Brim Box and Mossa, 1999; Osterling et al., 2010). Mussels are also sensitive to the excess of herbicides, pesticides and nutrients applied in monoculture plantations and flowing to aquatic ecosystems (Dudgeon et al., 2006; Strayer and Dudgeon, 2010). For instance Chellaiah and Yule (2017) showed that streams flowing through oil-palm plantations had higher phosphorous and potassium and lower sodium concentrations than streams in native forests, which was attributed to the use of fertilizers. In addition, unionid mussels have an obligatory larval parasitic stage on fish host that are in turn sensitive to habitat degradation, further reducing mussel reproduction and recruitment (Osterling et al., 2010; Santos et al., 2015).

\subsection{Effects of climate change on freshwater diversity in Sundaland}

The degradation of freshwater habitats caused by deforestation is reinforced by on-going climate changes that often result in a decrease of canopy shading, oxygen concentration in water, loss of connectivity that affects the availability of fish hosts, and in extreme cases temporal or permanent desiccation of freshwater habitats (Hastie et al., 2003; Meyer et al., 1999). Climate change projections in Sundaland anticipate higher frequency of disturbance events (e.g. storms, floods, droughts) related to El Niño/La Niña cycles (IPCC, 2014). In accordance, our models suggest a $30 \%$ reduction in the area suitable for native mussels in Sundaland under future climate change scenarios.

In the face of rapid climate changes, native mussel distributions will change, tracking climatically favourable habitat (Poff et al., 2012); a challenge exacerbated by the fragmentation of the remaining aquatic habitat, and by the mussels' strong dispersal limitation that depends on mobile or migratory fish hosts (Lopes-Lima et al., 2017). In fact, the timing of mussel and fish host reproductive cycles is usually linked, so that differential effects of temperature change may cause problems by uncoupling the timing of mussel and host reproduction (Hastie et al., 2003). Although very little is known about the mussel-host relationship in Sundaland, long-term survival clearly depends on host availability, so that changes in fish density and diversity will certainly pose a threat to mussel populations. Results from our study are in line with previous investigations exploring the joint consequences of future deforestation and climate change for the conservation of biodiversity in Sundaland. For instance, Struebig et al. (2015) projected 15-30\% loss of suitable habitat for orangutan by 2080 under land-use change scenarios; a figure that increased to $74 \%$ when considering climate change. Likewise, Brodie (2016) anticipated major altitudinal expansion of the cultivation zone for oil-palm, which is expected to result in a reduction of mammal ranges by $47-67 \%$ in 2070 .

\subsection{Effects of invasive species on freshwater diversity in Sundaland}

The expansion of the invasive $S$. woodiana is, according to our models, facilitated by road development associated with palm plantations and emerging population settlements, in line with previous investigations in the study area (Zieritz et al., 2018). Roads provide a common pathway for invasive species, particularly plants (e.g. Joly et al., 2011), but can also be relevant to explain the distribution of aquatic invaders (Gallardo et al., 2015b). Thus, by incorporating variables related to the vectors of introduction, our models go beyond habitat suitability and locate areas at regional scale where optimum climate and human conditions may facilitate the expansion of the species (Gallardo et al., 2015b). In particular, our models suggest that 32 Mha of Sundaland are currently suitable for colonization by the invasive S. woodiana, a figure that increases to 49 Mha under future climate change scenarios.

The overlap between the habitat suitable for native and invasive mussels shown in Fig. 3e increases from 16 Mha under the current scenario (which constitutes $43 \%$ of the native's suitable habitat) to 21 Mha under the 2050 pessimistic scenario (58\% of the native's suitable habitat), thus suggesting that native mussels will have to compete for habitat, resources and fish hosts with the invasive mussel across most of their natural range.

It must be noted, however, that even if the invasive species becomes established, it does not necessarily entail the immediate disappearance of native species because of local microrefugia or niche partitioning between species. Actually, no studies have yet investigated the direct interaction between S. woodiana and native mussels in Sundaland. For instance, Ricciardi et al. (1998) anticipated accelerating extirpation rates of 60 endemic freshwater mussel species in the Mississippi River after the arrival of the zebra mussel (Dreissena polymorpha). While freshwater mussel diversity is certainly declining in North America (Ricciardi and Rasmussen, 1999), their predictions were fortunately 


\section{Excluding oil-palm}
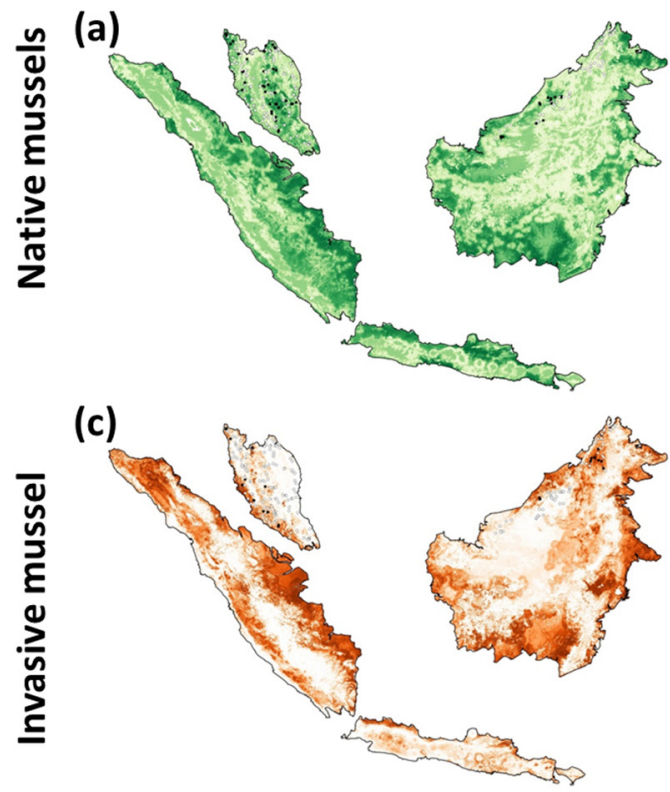

Including oil-palm

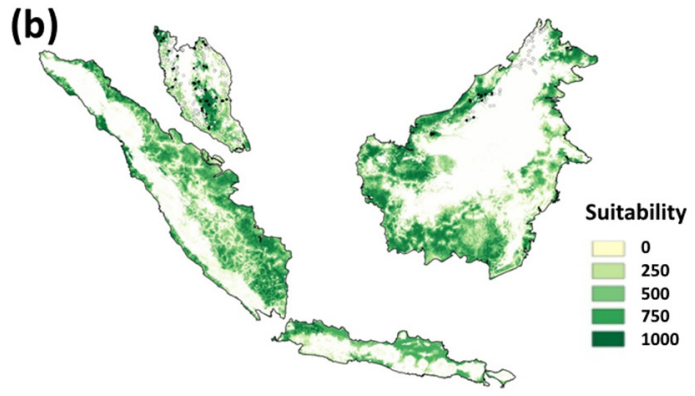

(d)

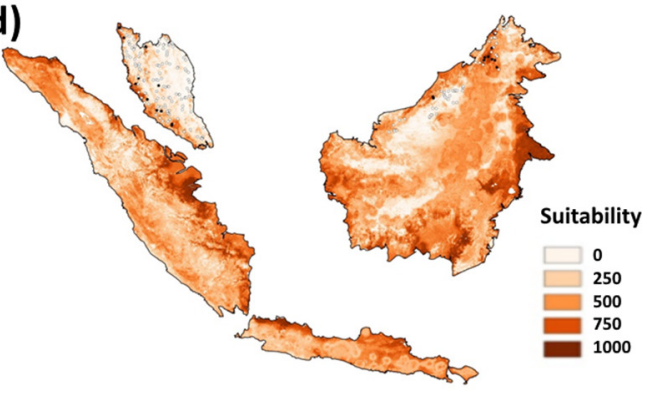

(e)

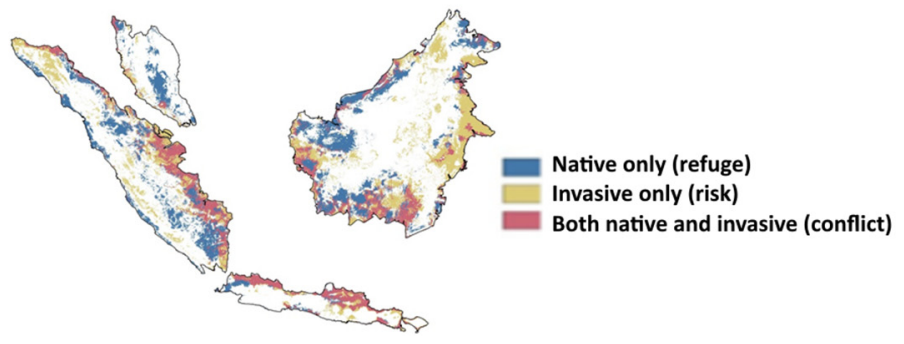

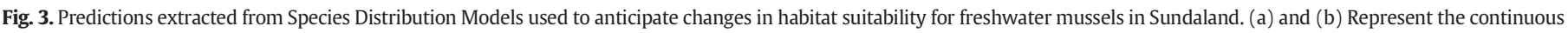

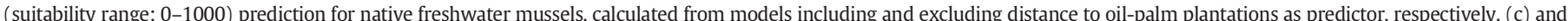

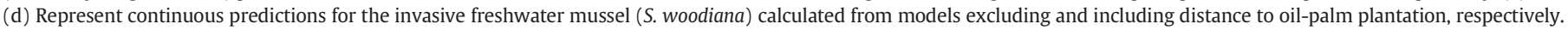

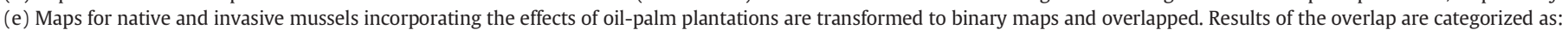

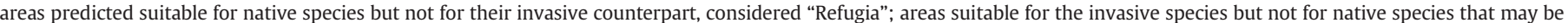
thus under a high "risk" of invasion; areas suitable for both native and invasive mussels where "conflicts" may arise.

not fully met, which was related to the strong context-dependency of the impacts of invasions, including invasive bivalves (Gallardo et al., 2015a; Ricciardi et al., 2013).

The comparison between the global and regional distribution models for $S$. woodiana provides further insights into the species' stage of invasion and future prospects (following the framework proposed by Gallien et al., 2012). Most of the invasive populations of $S$. woodiana in Malaysia can be correctly predicted by both the global and regional models (88\%), which suggest stabilizing populations with ample room for further expansion. Differences between the global and regional predictions can be partly explained by intraspecific variability: the global model is based on the species' wider ecological niche, incorporating climate preferences from populations as distant apart as Europe, North America and China. However, DNA sequence data indicate that the tropical lineage of $S$. woodiana differs from the European to the point that they may be considered different species (Bolotov et al., 2016), and is also different from the native populations in China (Zieritz et al., 2018). For this reason, regional models based on Sundaland's populations of $S$. woodiana may be more realistic to anticipate the potential expansion of the species. In fact, the global model failed to predict as suitable $12 \%$ of the sites already colonized by the species, which could be interpreted as populations undergoing adaptation to local conditions (Gallien et al., 2012).
4.4. Synergistic effects of global change on freshwater diversity in Sundaland

The independent effects of deforestation, climate change and invasive species can be sometimes detected immediately, but it often takes considerable amount of time for declining populations to disappear following environmental perturbations, incurreing in certain "extinction debt" (sensu Tilman et al., 1994). Direct and indirect consequences of these three major drivers of change on native freshwater mussels are synthesized in Fig. 4, where the size of arrows reflects results obtained in this study. For instance, deforestation causes the local extirpation of freshwater taxa directly by habitat loss and degradation (e.g. siltation, excess of nutrients and pollutants) (Chellaiah and Yule, 2017). But deforestation can also be indirectly responsible for lagged extirpations by facilitating invasions (Didham et al., 2007), and reducing the availability of fish hosts necessary for mussel recruitment (Österling and Högberg, 2014). Likewise, climate change can directly extirpate mussel populations if the upper temperature threshold of survival (at $32{ }^{\circ} \mathrm{C}$ according to Pandolfo et al., 2010) is exceeded, or by the increased frequency of extreme events such as droughts and floods (Sousa et al., 2012). But it is more likely to affect native species indirectly, through promoted expansion of invasive species (Gallardo and Aldridge, 2013a), lower availability of fish hosts (Hastie et al., 2003), and the expansion of oil palm plantations into areas that are currently unsuitable 


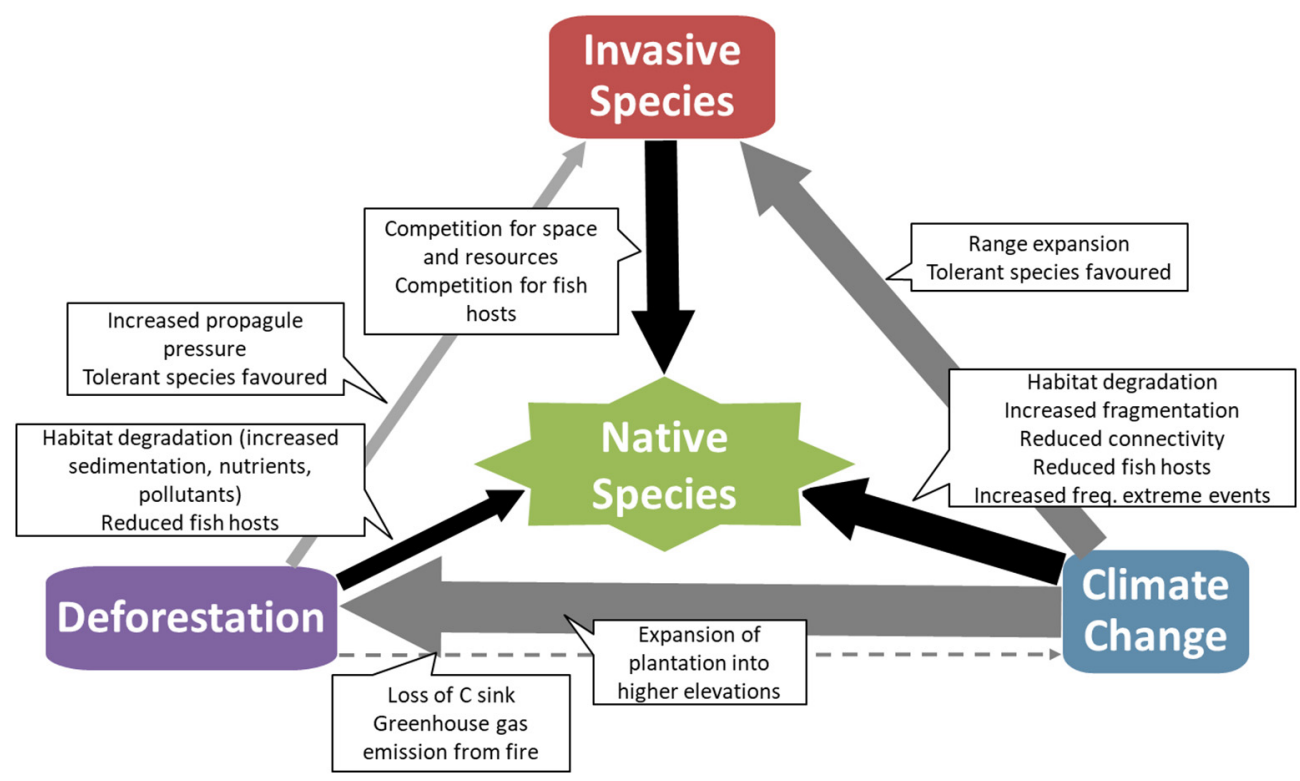

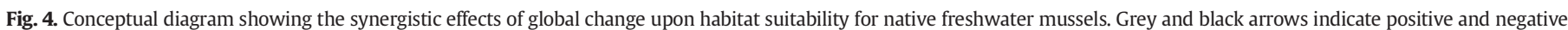

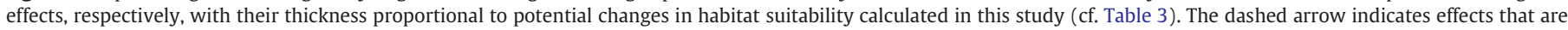

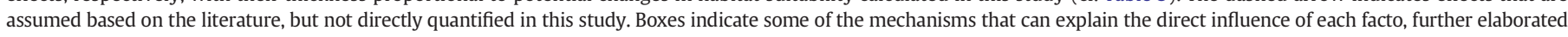
in the text.

for cultivation (Brodie, 2016). Consequently, the combined effects of the three factors are far more important than their independent effects (Brook et al., 2008).

\subsection{Model considerations}

In this study we calculated the area suitable for cultivation of oilpalm following a standard approach validated in the literature (Brodie, 2016; Struebig et al., 2015). While results are in agreement with past trends in oil palm expansion as well as with future forecasts (Wicke et al., 2011), we should note that other socio-economic factors not considered here may ultimately determine the magnitude and spatial distribution of oil palm plantations. Most notably, recent oil palm expansion has predominantly occurred in peatlands and other marginal lands of Sundaland, suggesting that oil palm development does not necessarily rely on habitat suitability (Koh et al., 2011). In spite of the inherent uncertainty associated to oil palm demand and cultivation, suitability assessments are still useful to predict where land-use impacts are likely to be most severe (Struebig et al., 2015). This is important, since the global demand of palm oil has been predicted to double by 2050 , requiring at least another $12-19$ Mha of cultivated areas globally (Corley, 2009).

Species Distribution Models are increasingly used to support conservation decision making, particularly to prevent and manage invasions (Guisan et al., 2013). Yet, distribution models are still limited to capture the fundamental nature of freshwater ecosystems-linear, dendritic landscapes characterized by numerous natural and artificial barriersthat underpin their vulnerability to global drivers of change (Poff et al., 2012). Models are therefore based on the unrealistic assumption that the current distribution of aquatic species are in equilibrium with their environment, and consequently, that species cannot dynamically adapt to changing conditions (Poff et al., 2012). Based on previous knowledge about the species' regional environmental preferences (Zieritz et al., 2016) and apparent vulnerability (Zieritz et al., 2018), we followed a precautionary approach and assumed that native freshwater mussels may indeed have little capacity of adaptation to changing conditions and dispersal between fragmented suitable habitats. However, such limitations are not likely to affect the invasive $S$. woodiana whose potential expansion due to human activities may be even larger than anticipated here.

Distribution models are often forced to extrapolate into areas outside the training range with no clear indication of uncertainty (Elith et al., 2010). High uncertainty does not necessarily mean incorrect predictions, but that the model is forced to extrapolate relationships. In our case, areas predicted as suitable for both native and invasive species, predominantly lowland rivers close to the coast, tend to show low uncertainty (Fig. S6). The high uncertainty areas are rather located at high altitude and slope, which are not commonly inhabited by tropical filter-feeding freshwater mussels, which are almost exclusively limited to the lower courses of rivers (Zieritz et al., 2017).

In the present work, we grouped nine native species for modelling, which allowed us to use all available information on freshwater mussel distribution in Malaysia-including rare, threatened species-and to investigate the group of freshwater mussels in a broader sense. The habitat suitability of each species will ultimately depend on the unique biological characteristics of its populations (life-history traits), including the interaction with other species (host specificity), as well as on how they cope with the drivers of change. This means that the real distribution of individual species is probably much more limited than suggested here, a situation especially worrisome for threatened species with a restricted spatial distribution.

\section{Conclusions}

This study is especially timely given the last decade's boom in oil palm production fuelled by growing global demands (Corley, 2009), which, together with on-going climate changes and unprecedented expansion of invasive species is expected to have catastrophic consequences for biodiversity conservation (Koh and Wilcove, 2008). Here we focus our attention on the potential impacts on freshwater mussels, a particularly vulnerable group facing global declines (Lydeard et al., 2004) that provides compelling indications of overall freshwater biodiversity. Endemic native species that are already rare, have very low dispersal potential, and very specific habitat and host requirements, are especially vulnerable to such combination. This is illustrated by recent evidence that the distribution of native freshwater mussels in Borneo has contracted considerably over recent decades, with $80 \%$ of its five 
endemic species suspected to be extinct (Zieritz et al., 2018). Altogether, our models suggest that plantations of oil-palm may decrease the total habitat suitable for native freshwater mussel species in Sundaland by $20 \%$, a figure that increases to $30 \%$ by 2050 when considering concomitant climate change, and almost triples (approx. 60\%) if we assume a negative influence of invasive species in areas of conflict. Our study identifies large areas in the east of Java, Sumatra and South-west of Borneo where conflicts between native and invasive species are likely to arise under a range of climate and land-use scenarios, and that should be prioritized for active management. Our projections further reveal that the potential Refugia remaining for native mussels are highly fragmented across Sundaland, which will further challenge mussel recruitment and survival. Location and protection of native species of extraordinary ecosystem importance, such as freshwater mussels, is imperative when considering the alarming rate of freshwater biodiversity decline and associated threats to human water security.

\section{Data accessibility statement}

All data and habitat suitability maps generated for this study as well as $\mathrm{R}$ scrips are available from the authors upon request.

\section{Acknowledgements}

This study is funded by the Malaysian Ministry of Higher Education (Project FRGS/1/2015/WAB13/UNIM//1). BG was supported by a research fellowship funded by the Spanish Program of R + D + I (JCI2012-11908). AZ, AB, SH, LJ, ML, KAR and RS conducted field samplings, BG and MP ran analyses, all authors contributed to writing the manuscript.

\section{Appendix A. Supplementary data}

Supplementary data to this article can be found online at https://doi. org/10.1016/j.scitotenv.2018.04.056.

\section{References}

Aldridge, D.C., Fayle, T.M., Jackson, N., 2007. Freshwater mussel abundance predicts biodiversity in UK lowland rivers. Aquat. Conserv. Mar. Freshwat. Ecosyst. 17, 554-564.

Barbet-Massin, M., Jiguet, F., Albert, C.H., Thuiller, W., 2012. Selecting pseudo-absences for species distribution models: how, where and how many? Methods Ecol. Evol. 3, 327-338.

Bogan, A.E., 2008. Global diversity of freshwater mussels (Mollusca, Bivalvia) in freshwater. Hydrobiologia 595, 139-147.

Bolotov, I.N., Bespalaya, Y.V., Gofarov, M.Y., Kondakov, A.V., Konopleva, E.S., Vikhrev, I.V. 2016. Spreading of the Chinese pond mussel, Sinanodonta woodiana, across Wallacea: one or more lineages invade tropical islands and Europe. Biochem. Syst. Ecol. 67, $58-64$.

Brim Box, J., Mossa, J., 1999. Sediment, land use, and freshwater mussels: prospects and problems. J. N. Am. Benthol. Soc. 18, 99-117.

Brodie, J.F., 2016. Synergistic effects of climate change and agricultural land use on mammals. Front. Ecol. Environ. 14, 20-26.

Broennimann, O., Guisan, A., 2008. Predicting current and future biological invasions: both native and invaded ranges matter. Biol. Lett. 4, 585-589.

Brook, B.W., Sodhi, N.S., Bradshaw, C.J.A., 2008. Synergies among extinction drivers under global change. Trends Ecol. Evol. 23, 453-460.

Brühl, C.A., Eltz, T., 2010. Fuelling the biodiversity crisis: species loss of ground-dwelling forest ants in oil palm plantations in Sabah, Malaysia (Borneo). Biodivers. Conserv. 19, 519-529.

Capinha, C., Essl, F., Seebens, H., Moser, D., Pereira, H.M., 2015. The dispersal of alien species redefines biogeography in the Anthropocene. Science 348, 1248-1251.

Chellaiah, D., Yule, C.M., 2017. Effect of riparian management on stream morphometry and water quality in oil palm plantations in Borneo. Limnol. Ecol. Manag. Inland Waters $69,72-80$.

Collen, B., Whitton, F., Dyer, E.E., Baillie, J.E.M., Cumberlidge, N., Darwall, W.R.T., et al., 2014. Global patterns of freshwater species diversity, threat and endemism. Glob. Ecol. Biogeogr. 23, 40-51.

Corley, R., 2009. How much palm oil do we need? Environ. Sci. Pol. 12, 134-139.

Danielsen, F., Heegaard, M., 1995. Impact of logging and plantation development on species diversity: a case study from Sumatra. Management of Tropical Forests: Towards an Integrated Perspective, pp. 73-92.
Didham, R.K., Tylianakis, J.M., Gemmell, N.J., Rand, T.A., Ewers, R.M., 2007. Interactive effects of habitat modification and species invasion on native species decline. Trends Ecol. Evol. 22, 489-496.

Donrovich, S.W., Douda, K., Plechingerová, V., Rylková, K., Horký, P., Slavík, O., et al., 2017. Invasive Chinese pond mussel Sinanodonta woodiana threatens native mussel reproduction by inducing cross-resistance of host fish. Aquat. Conserv. Mar. Freshwat. Ecosyst. https://doi.org/10.1002/aqc.2759.

Dormann, C.F., Elith, J., Bacher, S., Buchmann, C., Carl, G., Carré, G., et al., 2013. Collinearity: a review of methods to deal with it and a simulation study evaluating their performance. Ecography 36, 027-046.

Douglas, I., Spencer, T., Greer, T., Bidin, K., Sinun, W., Meng, W.W., 1992. The impact of selective commercial logging on stream hydrology, chemistry and sediment loads in the Ulu Segama rain forest, Sabah, Malaysia. Philos. Trans. R. Soc. Lond. Ser. B Biol. Sci. 335, 397-406.

Dudgeon, D, 2003. The contribution of scientific information to the conservation and management of freshwater biodiversity in tropical Asia. In: Martens, K. (Ed.), Aquatic Biodiversity: A Celebratory Volume in Honour of Henri J. Dumont. Springer, Netherlands, Dordrecht, pp. 295-314.

Dudgeon, D., Arthington, A.H., Gessner, M.O., Kawabata, Z.I., Knowler, D.J., Lévêque, C., et al., 2006. Freshwater biodiversity: importance, threats, status and conservation challenges. Biol. Rev. 81, 163-182.

Elith, J., Kearney, M., Phillips, S., 2010. The art of modelling range-shifting species. Methods Ecol. Evol. 1, 330-342.

Fitzherbert, E.B., Struebig, M.J., Morel, A., Danielsen, F., Brühl, C.A., Donald, P.F., et al., 2008. How will oil palm expansion affect biodiversity? Trends Ecol. Evol. 23, 538-545.

Gallardo, B., Aldridge, D.C., 2013a. Evaluating the combined threat of climate change and biological invasions on endangered species. Biol. Conserv. 160, 225-233.

Gallardo, B., Aldridge, D.C., 2013b. Priority setting for invasive species management: integrated risk assessment of multiple Ponto Caspian invasive species into Great Britain. Ecol. Appl. 23, 352-364.

Gallardo, B., Errea, M., Aldridge, D.C., 2012. Application of bioclimatic models coupled with network analysis for risk assessment of the killer shrimp, Dikerogammarus villosus, in Great Britain. Biol. Invasions 14, 1265-1278.

Gallardo, B., Zu Ermgassen, P.S.E., Aldridge, D.C., 2013. Invasion ratcheting in the zebra mussel (Dreissena polymorpha) and the ability of native and invaded ranges to predict its global distribution. J. Biogeogr. 40, 2274-2284.

Gallardo, B., Clavero, M., Sanchez, M.I., Vilà, M., 2015a. Global ecological impacts of invasive species in aquatic ecosystems. Glob. Chang. Biol. 22, 151-163.

Gallardo, B., Zieritz, A., Aldridge, D.C., 2015b. The importance of the human footprint in shaping the global distribution of terrestrial, freshwater and marine invaders. PLoS One 10 , e0125801.

Gallien, L., Douzet, R., Pratte, S., Zimmermann, N.E., Thuiller, W., 2012. Invasive species distribution models - how violating the equilibrium assumption can create new insights. Glob. Ecol. Biogeogr. 21, 1126-1136.

Giam, X., Koh, L.P., Tan, H.H., Miettinen, J., Tan, H.T., Ng, P.K., 2012. Global extinctions of freshwater fishes follow peatland conversion in Sundaland. Front. Ecol. Environ. 10, 465-470.

Giam, X., Hadiaty, R.K., Tan, H.H., Parenti, L.R., Wowor, D., Sauri, S., et al., 2015. Mitigating the impact of oil-palm monoculture on freshwater fishes in Southeast Asia. Conserv. Biol. 29, 1357-1367.

Graf, D.L., Cummings, K.S., 2015. The freshwater mussels (Unionoida) of the World (and other less consequential bivalves), updated 5 August 2015 MUSSEL Project Web Site.

Guisan, A., Thuiller, W., 2005. Predicting species distribution: offering more than simple habitat models. Ecol. Lett. 8, 993-1009.

Guisan, A., Tingley, R., Baumgartner, J.B., Naujokaitis-Lewis, I., Sutcliffe, P.R., Tulloch, A.I.T., et al., 2013. Predicting species distributions for conservation decisions. Ecol. Lett. 16, 1424-1435.

Hastie, L.C., Cosgrove, P.J., Ellis, N., Gaywood, M.J., 2003. The threat of climate change to freshwater pearl mussel populations. AMBIO J. Hum. Environ. 32, 40-46.

IPCC, 2014. Climate Change 2014-Impacts, Adaptation and Vulnerability: Regional Aspects. Cambridge University Press.

Joly, M., Bertrand, P., Gbangou, R.Y., White, M.-C., Dube, J., Lavoie, C., 2011. Paving the way for invasive species: road type and the spread of common ragweed (Ambrosia artemisifolia). Environ. Manag. 48, 514-522.

Koh, L.P., Wilcove, D.S., 2008. Is oil palm agriculture really destroying tropical biodiversity? Conserv. Lett. 1, 60-64.

Koh, L.P., Miettinen, J., Liew, S.C., Ghazoul, J., 2011. Remotely sensed evidence of tropical peatland conversion to oil palm. Proc. Natl. Acad. Sci. 108, 5127-5132.

Kraszewski, A., Zdanowski, B., 2007. Sinanodonta woodiana (Lea, 1834) (Mollusca) - a new mussel species in Poland: occurrence and habitat preferences in a heated lake system. Pol. J. Ecol. 55, 337-356.

Lopes-Lima, M., Sousa, R., Geist, J., Aldridge, D.C., Araujo, R., Bergengren, J., et al., 2017. Conservation status of freshwater mussels in Europe: state of the art and future challenges. Biol. Rev. 92, 572-607.

Lydeard, C., Cowie, R.H., Ponder, W.F., Bogan, A.E., Bouchet, P., Clark, S.A., et al., 2004. The global decline of nonmarine mollusks. Bioscience 54, 321-330.

McGarvey, D.J., Menon, M., Woods, T., Tassone, S., Reese, J., Vergamini, M., et al., 2017. On the use of climate covariates in aquatic species distribution models: are we at risk of throwing the baby out? Ecography 41 (4), 695-712.

Mercer, E.V., Mercer, T.G., Sayok, A.K., 2014. Effects of forest conversions to oil palm plantations on freshwater macroinvertebrates: a case study from Sarawak, Malaysia. J. Land Use Sci. 9, 260-277.

Meyer, J.L., Sale, M.J., Mulholland, P.J., Poff, N.L., 1999. Impacts of climate change on aquatic ecosystem functioning and health. J. Am. Water Res. Assoc. 35, 1373-1386. 
Miettinen, J., Shi, C., Liew, S.C., 2016. 2015 Land cover map of Southeast Asia at $250 \mathrm{~m}$ spatial resolution. Remote Sens. Lett. 7, 701-710.

Myers, N., Mittermeier, R.A., Mittermeier, C.G., da Fonseca, G.A.B., Kent, J., 2000. Biodiversity hotspots for conservation priorities. Nature 403, 853-858.

Österling, M., Högberg, J.-O., 2014. The impact of land use on the mussel Margaritifera margaritifera and its host fish Salmo trutta. Hydrobiologia 735, 213-220.

Osterling, M.E., Arvidsson, B.L., Greenberg, L.A., 2010. Habitat degradation and the decline of the threatened mussel Margaritifera margaritifera: influence of turbidity and sedimentation on the mussel and its host. J. Appl. Ecol. 47, 759-768.

Pandolfo, T.J., Cope, W.G., Arellano, C., Bringolf, R.B., Barnhart, M.C., Hammer, E., 2010. Upper thermal tolerances of early life stages of freshwater mussels. J. N. Am. Benthol. Soc. 29, 959-969.

Paunovic, M., Csányi, B., Simic, V., Stojanovic, B., Cakic, P., 2006. Distribution of Anodonta (Sinanodonta) woodiana (Rea, 1834) in inland waters of Serbia. Aquat. Invasions 1, 154-160.

Phillips, S.J., Dudik, M., Elith, J., Graham, C.H., Lehmann, A., Leathwick, J., et al., 2009. Sample selection bias and presence-only distribution models: implications for background and pseudo-absence data. Ecol. Appl. 19, 181-197.

Poff, N.L., Olden, J.D., Strayer, D.L., 2012. Climate change and freshwater fauna extinction risk. In: Hannah, L. (Ed.), Saving a Million Species: Extinction Risk from Climate Change. Island Press/Center for Resource Economics, Washington, DC, pp. 309-336.

R Core Team, 2017. R: A Language and Environment for Statistical Computing. R Foundation for Statistical Computing, Vienna, Austria.

Ricciardi, A., Rasmussen, J.B., 1999. Extinction rates of North American freshwater fauna. Conserv. Biol. 13, 1220-1222.

Ricciardi, A., Neves, R.J., Rasmussen, J.B., 1998. Impending extinctions of North American freshwater mussels (Unionoida) following the zebra mussel (Dreissena polymorpha) invasion. J. Anim. Ecol. 67, 613-619.

Ricciardi, A., Hoopes, M.F., Marchetti, M.P., Lockwood, J.L., 2013. Progress toward understanding the ecological impacts of nonnative species. Ecol. Monogr. 83, 263-282.

Sanderson, E.W., Jaiteh, M., Levy, M.A., Redford, K.H., Wannebo, A.V., Woolmer, G., 2002. The human footprint and the last of the wild. Bioscience 52, 891-904.

Santos, R., Fernandes, L.S., Varandas, S., Pereira, M., Sousa, R., Teixeira, A., et al., 2015. Impacts of climate change and land-use scenarios on Margaritifera margaritifera, an environmental indicator and endangered species. Sci. Total Environ. 511, 477-488.
Sodhi, N.S., Koh, L.P., Brook, B.W., Ng, P.K., 2004. Southeast Asian biodiversity: an impending disaster. Trends Ecol. Evol. 19, 654-660.

Soroka, M., 2005. Genetic variability among freshwater mussel Anodonta woodiana (Lea, 1834) (Bivalvia: Unionidae) populations recently introduced in Poland. Zool. Sci. 22, 1137-1144.

Sousa, R., Varandas, S., Cortes, R., Teixeira, A., Lopes-Lima, M., Machado, J., et al., 2012 Massive die-offs of freshwater bivalves as resource pulses. Annales de LimnologieInternational Journal of Limnology. vol. 48. EDP Sciences, pp. 105-112.

Sousa, R., Novais, A., Costa, R., Strayer, D.L., 2014. Invasive bivalves in fresh waters: impacts from individuals to ecosystems and possible control strategies. Hydrobiologia 735, 233-251.

Strayer, D.L., Dudgeon, D., 2010. Freshwater biodiversity conservation: recent progress and future challenges. J. N. Am. Benthol. Soc. 29, 344-358.

Struebig, M.J., Fischer, M., Gaveau, D.L., Meijaard, E., Wich, S.A., Gonner, C., et al., 2015. Anticipated climate and land-cover changes reveal refuge areas for Borneo's orangutans. Glob. Chang. Biol. 21, 2891-2904.

Thuiller, W., Georges, D., Engler, R., 2014. biomod2: ensemble platform for species distribution modeling. http://CRAN.R-project.org/package=biomod2.

Tilman, D., May, R.M., Lehman, C.L., Nowak, M.A., 1994. Habitat destruction and the extinction debt. Nature 371, 65-66.

Wicke, B., Sikkema, R., Dornburg, V., Faaij, A., 2011. Exploring land use changes and the role of palm oil production in Indonesia and Malaysia. Land Use Policy 28, 193-206.

Williams, J.D., Warren, M.L., Cummings, K.S., Harris, J.L., Neves, R.J., 1993. Conservation status of fresh-water mussels of the United-States and Canada. Fisheries 18, 6-22.

Yue, S., Brodie, J.F., Zipkin, E.F., Bernard, H., 2015. Oil palm plantations fail to support mammal diversity. Ecol. Appl. 25, 2285-2292.

Zieritz, A., Lopes-Lima, M., Bogan, A.E., Sousa, R., Walton, S., Rahim, K.A.A., et al., 2016. Factors driving changes in freshwater mussel (Bivalvia, Unionida) diversity and distribution in Peninsular Malaysia. Sci. Total Environ. 571, 1069-1078.

Zieritz, A., Bogan, A.E., Froufe, E., Klishko, O., Kondo, T., Kovitvadhi, U., et al., 2017. Diversity, biogeography and conservation of freshwater mussels (Bivalvia: Unionida) in East and Southeast Asia. Hydrobiologia 810, 29-44.

Zieritz, A., Bogan, A.E., Rahim, K.A.A., Sousa, R., Jainih, L., Harun, S., et al., 2018. Changes and drivers of freshwater mussel diversity and distribution in northern Borneo. Biol. Conserv. 219, 126-137. 